\title{
GRANDES PROJETOS, MERCADO DE TRABALHO E CONDIÇÕES DE RENDA E POBREZA DE REGIÕES IMPACTADAS: UMA ANÁLISE DO COMPLEXO PETROQUÍMICO DO RIO DE JANEIRO (COMPERJ)
}

\author{
LARGE PROJECTS, LABOR MARKET, INCOME CONDITIONS AND POVERTY \\ IN THE IMPACTED REGIONS: AN ANALYSIS OF THE PETROCHEMICAL COM- \\ PLEX OF RIO DE JANEIRO (COMPERJ)
}

\author{
Jorge Britto* \\ Carlos E. Guanziroli* \\ Daniel Ribeiro de Oliveira* \\ Caroline Cabral Machado* \\ Fernanda da Costa Nogueira*
}

enviado: 7 diciembre 2016 - aceptado: 15 mayo 2017

\begin{abstract}
Resumo
Dentre os diversos projetos industriais de grande porte em curso no país, o Complexo Petroquímico do Rio de Janeiro (COMPERJ) destaca-se como o maior investimento industrial da Petrobras em andamento no país, com impactos potenciais sobre o mercado de trabalho local extremamente relevantes. $\mathrm{O}$ artigo estrutura-se de modo a atingir dois objetivos. O primeiro deles, de natureza mais geral, compreende a caracterização do contexto socioeconômico da região impactada pelo COMPERJ, de forma identificar aspectos que constituem estímulos e entraves ao processo de desenvolvimento local, a partir dos impactos dos investimentos previstos para a região. O segundo objetivo, de natureza mais específica, contempla uma análise dos determinantes dos níveis de emprego e pobreza na região impac-

\footnotetext{
* Fac. Economia da Universidade Federal Fluminense, Niterói, Brasil. Correio eletrônico: britto.jorge@gmail.com, carlos.guanzi@gmail.com, daniel.eco@uol.com.br, carolcabralm@msn.com, fecnog@ gmail.com.

- Britto, J., Guanziroli, C., Ribeiro de Oliveira, D., Cabral Machado, C., \& da Costa Nogueira, F. (2017). Grandes projetos, mercado de trabalho e condições de renda e pobreza de regiões impactadas: uma análise do complexo petroquímico do Rio de Janeiro (COMPERJ). Estudios económicos, 34 (68), 3-38.
} 
tada pelo COMPERJ, com base numa pesquisa primária de caráter domiciliar e no tratamento econométrico das informações levantadas.

Código JEL: J61, J81, J82, R11, R23.

Palavras-chave: Mercado de Trabalho Regional; Desenvolvimento Econômico Local; Migração Regional.

\begin{abstract}
Among the various large industrial projects currently underway in the country, the Rio de Janeiro Petrochemical Complex (COMPERJ) stands out as the biggest investment in the history of Petrobras in progress in the country, with potential impacts on the local labor market that seem to be extremely relevant. The article is structured to achieve two goals. The first one, of more general nature, comprises the characterization of the socioeconomic context of the region impacted by the COMPERJ, in order to identify aspects that constitute stimuli and barriers to local development process, from the impacts of investments to the region. The second objective, which is more specific, includes an analysis of the determinants of employment and poverty levels in the region impacted by COMPERJ, on the basis of a field research with households of the region. Data raised during the field research was analyzed using an econometric model.
\end{abstract}

JEL Code: J61, J81, J82, R11, R23.

Key Words: Regional Labor Markets, Local Economic Development; Regional Migration.

\title{
INTRODUÇÃO
}

Ao se discutir possíveis impactos de grandes projetos sobre o desenvolvimento das regiões adjacentes, uma questão particularmente importante refere-se à necessidade de se incorporar à análise procedimentos para avaliar os impactos efetivos sobre os níveis de emprego, renda e pobreza da população impactada. Dentre os diversos projetos industriais de grande porte em curso no país, o Complexo Petroquímico do Rio de Janeiro (COMPERJ) destaca-se como o maior investimento da história da Petrobras e o maior investimento industrial em andamento no país. Ao mesmo tempo, a região mais impactada diretamente por esse empreen- 
dimento compreende municípios da região Leste fluminense que se destacam em função dos menores níveis de industrialização e renda, em comparação com o conjunto do estado do Rio de janeiro. Esta região é composta por quatro municípios fluminenses: Cachoeiras de Macacu, Guapimirim, Itaboraí e Tanguá.

Considerando estes quatro municípios que serão mais afetados diretamente pelo empreendimento como recorte territorial, a análise desenvolvida no artigo estrutura-se de modo a atingir dois objetivos. O primeiro, de natureza mais geral, compreende a caracterização do contexto socioeconômico da região impactada, de forma identificar aspectos que constituem estímulos e entraves à dinamização do mercado de trabalho e ao processo de desenvolvimento local, considerando impactos dos investimentos. O segundo objetivo, de natureza mais específica, contempla uma análise dos determinantes dos níveis de emprego e pobreza na região impactada pelo COMPERJ, com base numa pesquisa primária de caráter domiciliar e no tratamento econométrico das informações levantadas. De modo a atingir esses objetivos, o artigo estrutura-se em seis seções. A primeira apresenta as características gerais do COMPERJ, sinalizando também possíveis impactos sobre a região adjacente. A segunda seção apresenta os conceitos que fundamentam a análise, baseada nas conexões entre desenvolvimento local, competitividade territorial e as condições de renda e pobreza da região considerada. A terceira seção apresenta um quadro socioeconômico geral dos municípios da área de influência do COMPERJ. A quarta seção apresenta a metodologia da pesquisa de campo desenvolvida para analisar as condições de renda nos municípios da Área de Influência do COMPERJ. A quinta seção desenvolve um modelo econométrico para analisar os determinantes dos níveis de renda nos municípios investigados. Uma última seção sumariza algumas conclusões do estudo.

\section{CARACTERÍSTICAS GERAIS DO COMPERJ}

O Complexo Petroquímico do Rio de Janeiro (COMPERJ) está sendo construído em uma área de $45 \mathrm{~km} 2$ no município de Itaboraí, na região metropolitana do Rio de Janeiro, envolvendo um investimento estimado de cerca de 8,30 bilhões de dólares - o maior investimento da história da Petrobras e industrial em andamento no país. $\mathrm{O}$ empreendimento deverá causar fortes impactos nas regiões Leste e Centro-Norte Fluminenses, em especial nos municípios de Cachoeiras de Macacu, Guapimirim, Itaboraí, Tanguá, Magé, Rio Bonito e São Gonçalo. Sua configuração inclui, em uma mesma área industrial, unidades de Refino e unidades Petroquímicas. Emsua primeira etapa, prevista para ser concluído em 2015, o COMPERJterá capacidade de processar 165 mil barris de petróleo por dia, abas- 
tecendo o mercado com óleo diesel (42,9 \% da produção), nafta petroquímica (22\%), querosene de aviação (16\%), coque (10\%), GLP $(5,5 \%)$ e óleo combustível $(4,1 \%)$. O segundo trem de refino do COMPERJ encontra-se em Fase de Avaliação e, provavelmente, terá capacidade de processar 300 mil barris de petróleo por dia, cuja operação está para ser iniciada em janeiro de 2018. Além dos trens de refino, o projeto COMPERJ ainda contará com unidades de produção de lubrificantes e aromáticos, bem como unidades de processamento do gás natural produzido no Pré-Sal, que também será utilizado como matéria-prima para as plantas petroquímicas. As unidades petroquímicas têm previsão de operação em 2018, produzindo eteno, propeno, estireno, polietilenos, polipropileno PTA e PET, entre outros petroquímicos. As empresas de $3^{a}$ geração, que poderão ser atraídas pelo COMPERJ a se instalarem nos municípios vizinhos e ao longo do Arco Metropolitano, que ligará Itaboraí ao Porto de Itaguaí, serão responsáveis por transformar esses produtos petroquímicos de $2^{\mathrm{a}}$ geração em bens de consumo.

Estima-se que o empreendimento apresenta um potencial de geração de mais de 200 mil empregos diretos, indiretos e por efeito renda. Durante as obras, as oportunidades de negócio encontram-se vinculadas à atuação na região de grandes empresas de engenharia (EPCistas) e ao fornecimento de local de bens e serviços. Identifica-se também uma demanda expressiva por moradia, comércio, serviço e educação/qualificação, graças ao grande contingente de mão de obra alocado no projeto. Em uma fase posterior de produção petroquímica, as oportunidades estão relacionadas à expansão da indústria de material plástico, já que a disponibilidade de matéria-prima para essas indústrias representa um importante fator para a atração de novos investidores.

As dimensões dos investimentos relacionados à viabilização do COMPERJ reforçam a necessidade de adequação da infraestrutura econômica e logística da região. Em especial, torna-se necessário estruturar um sistema de logística para escoamento da produção e recepção de petróleo bruto a ser utilizado no complexo. $\mathrm{O}$ gás natural a ser utilizado como insumo provavelmente será levado até o COMPERJ por gasodutos submarinos, que terão de 250 a 300 quilômetros (km) de extensão, cujo trajeto ainda está sendo estudado. Outra possibilidade para levar o gás até o COMPERJ é a utilização de navios gaseiros para liquefazer o gás natural no oceano e transportá-lo até um terminal de regaseificação no continente. A recepção dos equipamentos pesados do complexo vai exigir a construção de uma rodovia especial por uma área pouco habitada do município de São Gonçalo (localizado ao fundo da baía de Guanabara), evitando passar pela rodovia BR-101, de tráfego intenso. A Petrobras também vai construir um porto na Praia da Beira, em Itaoca, São Gonçalo, para receber os equipamentos de grande porte, que será 
ligado ao COMPERJ por estrada com 22 quilômetros, também a ser construída. Os investimentos de quase $\mathrm{R} \$ 500$ milhões da Petrobras vão auxiliar no transporte de equipamentos para o COMPERJ. Em uma possível ampliação, poderão ser feitas áreas de apoio offshore, áreas de construção de módulos e de construção de embarcações.

Uma das obras complementares ao COMPERJ mais importantes é o Arco Metropolitano do Rio de Janeiro, uma rodovia de pista dupla de $145 \mathrm{~km}$ interligando as principais vias de acesso à capital do Estado até o porto de Itaguaí. Um dos trechos da interligação é a rodovia BR-493, compreendendo trecho de $25 \mathrm{~km}$ entre a BR-101 e a BR-116. O Arco Metropolitano é uma das maiores obras já realizada em território fluminense, abrangendo trechos das rodovias RJ-106 (Amaral Peixoto) e RJ-114 (ligação dos municípios de Itaboraí e Maricá), proporcionando uma conexão logística com as rodovias RJ-116, que liga Itaboraí ao Município de Itaperuna, com a BR-101, na Baixada Fluminense, com uma ferrovia e com polos industriais de grande porte que estão sendo implantados na região. Uma das pontas do projeto é o Porto de Itaguaí, que operaria como corredor de exportação do COMPERJ, no escoamento da produção de derivados do petróleo. Outro projeto em gestação na região compreende o Porto de Jaconé, atrelado a um Polo Industrial Naval, no município de Maricá. O empreendimento, intitulado como Porto do Pré-Sal, envolveria investimentos da ordem de $\mathrm{R} \$ 5$ bilhões, e teria capacidade para receber 850 mil barris de petróleo por dia, o equivalente a $40 \%$ da atual produção do país. O porto deve destinar apenas $30 \%$ de sua capacidade à Petrobras. O restante será voltado para as companhias estrangeiras que atuarão no pré-sal. O terminal contará com atividade de apoio offshore e prevê um grande estaleiro para reparos. A região tende a ser impactada por investimentos upstream em atividades offshore - associados ao potencial de exploração de petróleo na camada pré-sal - e em outras atividades associadas, com aquelas vinculadas à infraestrutura portuária, dutoviária e à construção naval.

O incremento da demanda de bens e serviços a partir da montagem das unidades do COMPERJ, em suas diferentes etapas, combinada com os demais investimentos em curso na região, apresenta um expressivo potencial de expansão da economia local. Apesar da operação de refinarias e unidades petroquímicas ser dominada por grandes economias de escala e altos investimentos em tecnologia, que constituem elevadas barreiras à entrada de pequenos empreendimentos, existem espaços importantes para atuação de Micro e Pequenas Empresas (MPEs), especialmente nos serviços industriais. 
A manutenção do ritmo atual de realização de obras civis, com perspectiva inclusive de sua intensificação nos próximos anos, acrescida à realização de investimentos expressivos na infraestrutura logística e na infraestrutura urbana da região, tende a resultar em oportunidades de negócios interessantes, com potencial de dinamização da economia da região. A inserção de empresas locais em cadeias de fornecimento no estágio atual de construção do empreendimento contempla várias alternativas, através do suporte direto às obras de engenharia e da prestação de serviços técnicos especializados, do fornecimento de materiais de consumo, da prestação de serviços de contratação de mão de obra e segurança e da prestação de serviços gerais não especializados vinculados às áreas de alimentação, hospedagem, manutenção e atividades administrativas. No entanto, identificam-se dificuldades para incorporar produção local de máquinas e equipamentos, dada a escala da demanda viabilizar essa produção e localização pré-existente das empresas especializadas nessa produção em outras localidades. Em particular, observa-se que base local de produção de insumos e equipamentos é ainda limitada, com a estrutura do fornecimento local estando vinculada fundamentalmente à base logística de apoio às obras de engenharia pesada (no próprio COMPERJ e na infraestrutura que o circunda) e à prestação de uma série de serviços especializados. Nesse contexto, as MPEs dedicam-se principalmente à provisão local de serviços de menor complexidade tecnológica.

A dinamização da economia local, no contexto atual do empreendimento, encontra-se fortemente atrelada à dinâmica do setor de construção, civil e pesada. Em termos do setor de construção, dois tipos de impactos podem ser destacados. Os impactos diretos das obras estariam relacionados à realização de obras de terraplanagem (numa primeira etapa), à construção de redes de transportes por dutos, à montagem de instalações industriais e de estruturas metálicas e de instalações elétricas. Já os impactos sobre infraestrutura viária e urbana estariam relacionados à construção de rodovias e portos, à valorização e especulação fundiária e à construção de edifícios e outras unidades residenciais, com impactos na dinâmica urbana. Os impactos observados envolvem a instalação de construtoras na região, a criação de empregos, o estímulo ao suprimento local de insumos para construção civil e a dinamização comércio varejista de ferragens, madeira e materiais de construção. Além do aumento de contratação de mão de obra, o aumento da demanda por moradias e a elevação dos preços de terrenos constituem evidências desses impactos, fortalecidos também pela reativação de linhas o financiamento público, pelos investimentos em obras de infraestrutura, pelo deslocamento de novos residentes para a região e pela sofisticação da rede de serviços urbanos. 
Neste sentido, analisando o impacto de dois empreendimentos com características similares, a Refinaria do Planalto - REPLAN, no município de Paulínia, e a Unidade de Tratamento de Gás, Monteiro Lobato - UTGCA em Caraguatatuba, ambos no estado de São Paulo, Barbosa (2008) e Renk (2016) ressaltam que, ao analisar o discurso dos moradores das regiões produtoras, fica evidente a existência de conflitos significativos entre o aumento da oferta de emprego local, e os problemas que tais empreendimentos podem gerar nas modificações no cotidiano e nas condições de acesso da população local ao mercado de trabalho. Nas situações investigadas, os autores ressaltam que as transformações resultantes ocasionaram o surgimento de duas comunidades distintas: a local existente e o parque industrial em implantação, resultando num padrão urbano com características desiguais, caracterizado pelo inchaço da cidade em função do impacto de novas frentes de trabalho e do aumento populacional, aliado a um processo de especulação imobiliária levou ao surgimento de bairros cada vez mais distantes, afastados dos locais de trabalho e carentes de equipamentos urbanos e infraestrutura básica, impondo à sua população distâncias de deslocamento cada vez maiores, além de um aumento no custo de vida e de uma sobrecarga dos serviços públicos. Apesar desses impactos, a análise dos autores com população local indica que os impactos dos empreendimentos podem ser considerados mais positivos que negativos.

\section{DESENVOLVIMENTO LOCAL, COMPETITIVIDADE TERRITORIAL E CONDIÇÕES DE RENDA E POBREZA}

Em linhas gerais, a literatura de "desenvolvimento local" parte da hipótese de que a estruturação das atividades econômicas se articula às condições socioeconômicas da localidade na qual as mesmas se inserem (OCDE, 2001; Casanova, 2004). Além disso, esta literatura atribui particular ênfase a determinados fatores endógenos ao local que explicariam o maior ou menor dinamismo daquelas atividades, ressaltando, em especial, o papel desempenhado pela estruturação de redes sociais e econômicas, pela dotação de recursos humanos e pela presença de um arcabouço institucional que facilite as articulações entre os agentes. Em particular, este tipo de literatura busca articular a noção de proximidade a três modalidades de desenvolvimento: (i) uma proximidade geográfico-territorial, que estaria integrada à dimensão social, no sentido de criação de um sentido de "pertencimento" dos agentes em relação ao território que habitam; (ii) uma proximidade organizacional, relacionada ao estabelecimento de relações sistemáticas e duradouras entre os agentes e à consolidação de um quadro cognitivo comum; (iii) uma proximidade institucional, baseada disseminação de valores e na adesão consensual às regras de ação coletivamente definidas. 
$\mathrm{Na}$ análise dos possíveis impactos de grandes projetos sobre o desenvolvimento local, alguns desdobramentos analíticos interessantes emergem da articulação entre diferentes formas de "polarização" e os elementos definidores da competitividade territorial. No tocante ao fenômeno da polarização, é possível explorar o argumento de Paelinck (1977) que, partindo da análise original de Perroux (1955), distingue três formas de polarização que condicionam o desenvolvimento de uma determinada região: (i) uma polarização técnica, determinada pela capacidade de uma determinada atividade econômica estimular o crescimento de outras atividades tecnicamente ligadas a ela; (ii) uma polarização pelas rendas, resultante do efeito dinamizador sobre região decorrente da geração de rendas; (iii) uma polarização psicológica, decorrente do impacto que a localização de determinada atividade acarreta em termos de expectativas que condicionam o comportamento dos demais agentes econômicos; (iv) uma polarização geográfica, resultante do efeito gerado a partir da aglomeração de atividades em torno de uma indústria motriz, especialmente dos serviços produtivos.

A partir da conjunção desses elementos, se tornaria possível implementar estratégias de "baixo para cima" que teriam um maior potencial para impulsionar o desenvolvimento das diferentes localidades. Segundo White e Gasser (2001), estas estratégias estariam baseadas em quatro princípios gerais básicos: (i) a ênfase na participação e diálogo social entre os agentes locais; (ii) o reforço do enraizamento territorial; (iii) a mobilização de recursos locais visando obtenção de vantagens competitivas diferenciais; (iv) o comando e gerenciamento da estratégia por agentes locais. Do ponto de vista dos objetivos das estratégias de desenvolvimento local, a sistematização realizada em estudo da OCDE (2001) ressalta a importância dos seguintes fatores: (i) a criação de empregos; (ii) o fortalecimento de capacitações e da empregabilidade da força de trabalho através do treinamento; (iii) o estímulo a investimentos e o fortalecimento do empreendedorismo ao nível local; (iv) a assistência a segmentos mais desfavorecidos para reduzir desigualdade; (v) a melhoria da qualidade de vida através da provisão de serviços e de infraestrutura; (vi) o desenvolvimento de mecanismos de avaliação das ações e resultados; (vii) a possibilidade de reprodução-transferência de experiências bem-sucedidas.

Considerando esses elementos, torna-se possível articular analiticamente a avaliação dos impactos de um grande empreendimento com as características do COMPERJ às condições prevalecentes no mercado de trabalho e aos determinantes dos níveis de emprego, renda e pobreza da população do entorno mais próximo do empreendimento que, neste caso, corresponde aos Municípios de Itaboraí, Cachoeiras de Macacu, Tanguá e Guapimirim. Desse modo, as duas seções que se seguem procuram, respectivamente, apresentar um quadro geral das condições socioeconômicas 
prevalecentes nesses municípios, com base em informações secundárias, e discutir os fatores determinantes dos níveis de renda e pobreza naquelas localidades, a partir do levantamento de informações primárias e do tratamento econométrico das mesmas.

\section{MUNICÍPIOS DA ÁREA DE INFLUÊNCIA DO COMPERJ: QUADRO SÓCIO-ECONÔMICO E MERCADO DE TRABALHO}

A Tabela 1 apresenta alguns indicadores básicos que refletem a situação econômica atual da região composta, bem como características gerais do mercado de trabalho no caso de quatro municípios que conformam a área de influência diretas do COMPERJ (Cachoeiras de Macacu, Guapimirim, Itaboraí e Tanguá). Apesar das expectativas sobre os impactos de novos investimentos, observa-se que a região apresenta baixo dinamismo econômico, refletido na sua participação no PIB geral do estado do Rio de Janeiro em 2013 (1,15\%) apesar das evidências de possível reversão desse quadro no período recente, já como reflexo dos impactos dos investimentos da Petrobras na região. De fato, o Crescimento do PIB para o período 2006-2013 na região foi de $192 \%$, contra $127 \%$ para o conjunto do estado do Rio de Janeiro; já em termos do PIB industrial esse crescimento foi ainda mais intenso de $375 \%$ contra $112 \%$ para o conjunto do estado do Rio de Janeiro. É possível também observar baixos níveis de PIB per-capita nos municípios da região, comparativamente ao conjunto do estado, o que constitui evidência da presença de baixos níveis de desenvolvimento.

Em termos do comportamento do mercado de trabalho, a Tabela 1 aponta para uma taxa de desocupação, em relação à população economicamente ativa, de 11,17 \% para os municípios da área de influência do COMPERJ, segundo dados do Censo 2010, que é aproximadamente $31 \%$ superior à observada para o conjunto do estado do Rio de Janeiro. O percentual de trabalhadores com carteira assinada na região, de 61,8 \% segundo o censo 2010, era aproximadamente $11 \%$ inferior ao observado para o conjunto do estado do Rio de Janeiro. Na região foram gerado aproximadamente 53,9 mil postos de emprego formais em 2011, equivalentes a $1,24 \%$ dos empregos formais gerados no estado, com forte concentração no município de Itaboraí. Entre 2008-2013, o emprego formal na região cresceu 85,8 \% na região, comparativamente a um crescimento de $23,8 \%$ observado para o conjunto do estado. A remuneração média mensal do emprego formal na região atingia $\mathrm{R} \$ 1.979$ em 2013, aproximadamente $20 \%$ inferior à observada para o conjunto do estado. Entre 2008-2011, a remuneração média mensal do emprego formal na região cresceu 128 \% na região, equivalente a um crescimento de mais do dobro observado para o conjunto do estado. A situação de aquecimento do mercado de 
trabalho na região se reflete no montante do saldo líquido de admissões (descontados os desligamentos) observados na região em 2012, totalizando quase 7.400 admissões líquidas, fortemente concentradas em Itaboraí, que equivaliam a 7\% do saldo líquido de admissões observado para o conjunto do estado do Rio de Janeiro. Este aquecimento do mercado de trabalho encontra-se fortemente atrelado ao setor de construção civil, impactado diretamente pelas obras do COMPERJ.

Tabela 1. Informações sobre PIB, População e Mercado de Trabalho Municípios da Área de Influência Direta do COMPERJ

\begin{tabular}{|c|c|c|c|c|c|c|c|}
\hline & $\begin{array}{c}\text { PBI a } \\
\text { preços } \\
\text { correntes }^{1}\end{array}$ & $\begin{array}{cc}\text { Var PIB } & \text { Ind } \\
2006-2013 & \text { a p } \\
& \text { corr }\end{array}$ & $\begin{array}{ll}\text { VA } & \\
\text { ndústria } & \text { In } \\
\text { preços } & \text { a } \\
\text { rrentes }^{1} & \text { co }\end{array}$ & $\begin{array}{c}\text { VA } \\
\text { Indústria } \\
\text { a preços } \\
\text { correntes }\end{array}$ & opulação² & PIB p.c. ${ }^{1}$ & PEA $^{3}$ \\
\hline $\begin{array}{c}\text { Cachoeiras de } \\
\text { Macacu } \\
\end{array}$ & 1.005 & $63,5 \%$ & 203 & $49,3 \%$ & 55.632 & 18.067 & 26.780 \\
\hline Guapimirim & 721 & $128,3 \%$ & 94 & $63,7 \%$ & 54.706 & 13.188 & 25.266 \\
\hline Itaboraí & 5.019 & $267,3 \%$ & 1.544 & $729,7 \%$ & 225.263 & 22.282 & 107.392 \\
\hline Tanguá & 456 & $170,3 \%$ & 80 & $211,9 \%$ & 31.844 & 14.327 & 13.904 \\
\hline Região & 7.202 & $192,0 \%$ & 1.921 & $374,6 \%$ & 367.445 & 19.601 & 173.342 \\
\hline Rio de Janeiro & 626.320 & $127,5 \%$ & 62.520 & $112,2 \%$ & 6.369 .179 & 38.262 & 7.814.727 \\
\hline $\begin{array}{c}\text { \% ou } \\
\text { Comparação } \\
\end{array}$ & 1,15 & 1,51 & 1,18 & 3,34 & 2,24 & 51,23 & 2,22 \\
\hline & $\begin{array}{c}\text { Desocupados / } \\
\text { PEA }^{3}\end{array}$ & $\begin{array}{c}\% \\
\text { Empregados } \\
\text { com carteira } \\
\text { de trabalho } \\
\text { assinada }^{3} \\
\end{array}$ & $\begin{array}{l}\text { Emprego } \\
\text { sormal }{ }^{4}\end{array}$ & $\begin{array}{lc}\text { o } & \text { Cresc. } \\
4 & \text { Emprego } \\
& \text { Formal } \\
& \text { 2008-2013 }\end{array}$ & \multicolumn{2}{|c|}{$\begin{array}{c}\text { Remuneração } \\
\text { Média mensal } \\
\text { - Emprego } \\
\text { Formal }^{4}\end{array}$} & $\begin{array}{l}\text { ariação da } \\
\text { muneração } \\
\text { dia mensal - } \\
\text { rego Formal } \\
008 \text { - } 2013 \\
\end{array}$ \\
\hline $\begin{array}{c}\text { Cachoeiras de } \\
\text { Macacu }\end{array}$ & $9,71 \%$ & $59,3 \%$ & 8.386 & $10,4 \%$ & 1.48 & & $72,8 \%$ \\
\hline Guapimirim & $12,87 \%$ & $53,1 \%$ & 5.924 & $28,1 \%$ & 1.55 & & $95,3 \%$ \\
\hline Itaboraí & $11,21 \%$ & $63,9 \%$ & 50.214 & $128,1 \%$ & 2.16 & & $140,4 \%$ \\
\hline Tanguá & $10,54 \%$ & $66,3 \%$ & 4.218 & $52,9 \%$ & 1.35 & & $74,5 \%$ \\
\hline Região & $11,17 \%$ & $61,8 \%$ & 68.742 & $85,8 \%$ & 1.97 & & $127,6 \%$ \\
\hline Rio de Janeiro & $8,49 \%$ & $69,0 \%$ & 4.586 .790 & $23,6 \%$ & 2.46 & & $57,9 \%$ \\
\hline $\begin{array}{c}\text { \% ou } \\
\text { Comparação } \\
\end{array}$ & 1,315 & 0,892 & 1,50 & 3,64 & 0,80 & & 2,20 \\
\hline
\end{tabular}

Fonte: Elaboração própria a partir de dados do IBGE (Censo 2010 e PIB municipal) e da RAIS (MTe) Notas: 1: (R\$106) 2013; 2: ( $\mathrm{N}^{\circ}$ de habitantes) 2013 (estimativa); 3: (censo 2010); 4: R\$ 2013 
De modo a caracterizar mais detalhadamente os impactos atuais do empreendimento sobre o mercado formal de trabalho na região, foi considerado um conjunto de atividades selecionadas a partir das classes de atividades da CNAE 2.0, que foram reagrupadas em seis grandes grupos: 1) Indústrias de base Químicopetroquímica; 2) Indústrias de base Extrativa ou Metal-Mecânica; 3) Comércio e Produção de Máquinas; 4) Construção (Engenharia, Serviços e Materiais); 5) Atividades Logísticas; 6) Serviços Especializados Impactados. A Tabela 2 apresenta a evolução do peso dessas atividades no total do emprego formal e da remuneração gerada nos municípios da área de influência, e especificamente em Itaboraí entre 2006-2013, com base em informações da RAIS-MTe. No caso dos municípios da área de influência do CONLESTE o emprego nas atividades selecionadas era de $31,3 \%$ em 2006 e passa a 51,8 \% em 2012. Já no município de Itaboraí, essas atividades respondiam em 2006 por cerca de 36,9\% do emprego total no município enquanto que, em 2012, essa participação chega a $62,3 \%$. As informações apresentadas indicavam que o conjunto de atividades vinculadas ao setor de Construção, eram responsáveis por $37,3 \%$ do emprego formal na região em 2013 (percentual que se eleva a 46,7 \% em Itaboraí) e por 47,5 \% do montante de remuneração gerado por esses empregos (percentual que se eleva a 56,3\% em Itaboraí).Dentre as atividades selecionadas, um crescimento particularmente elevado da participação no total do emprego foi observado para os grupos de Comércio e Produção de Máquinas (de 0,8 \% em 2006 para 3,0 \% em 2013 na região e de 1,3 \% em 2006 para 3,4 \% em 2013 em Itaboraí), Construção (de 17,2 \% em 2006 para 37,3 \% em 2013 na região e de 21,1 \% em 2006 para 46,7\% em 2013 em Itaboraí. Em termos do total de remunerações, no caso dos municípios da área de influência direta do COMPERJ, essa participação se expande consideravelmente, evoluindo de 30,9\% em 2006 para 60,4 \% em 2013, crescimento estimulado, em boa medida, pelo crescimento daquela participação em Itaboraí, que evolui de 34,0 \% em 2006 para 70,3\% em 2013. Um crescimento particularmente elevado da participação no total das remunerações foi observado para os grupos de Construção (de 17,6 \% em 2006 para 45,7 \% em 2013 na região e de 18,8 \% em 2006 para 56,3\% em 2013 em Itaboraí). Assim, dada a natureza das atividades selecionadas é possível apontar para uma clara influência dos investimentos associados ao COMPERJ na expansão do emprego e da renda na região investigada.

A Tabela 3 apresenta informações que possibilitam um melhor entendimento da realidade socioeconômica dos municípios investigados. Um primeiro aspecto a ser considerado refere-se ao grau de escolaridade da população local, vista como uma "proxy" da qualidade do capital humano que pode atuar como fator de estímulo ou restrição à aceleração do processo de desenvolvimento local. As informações do Censo 2010 indicavam que 54 \% da população de 10 anos ou 
mais se apresentava sem instrução ou com o ensino fundamental incompleto, um percentual30 \% ao observado para o conjunto do estado do Rio de Janeiro. Em contraste, $26,8 \%$ dessa população local apresentava ensino médio completo ou superior (completo ou incompleto), percentual aproximadamente $30 \%$ inferior ao observado para o conjunto do estado, evidenciando uma inadequação às crescentes exigências de qualificação no acesso ao mercado de trabalho.

A Tabela 3 apresenta também informações sobre a importância dos fluxos migratórios e a pendularidade da força de trabalho, em termos de deslocamentos para fins de estudo ou trabalho. Segundo os dados do Censo 2010, 42,5 \% da população local não era natural do município em que habitava percentual expressivamente superior ao observado para o conjunto do estado do Rio de janeiro. As evidências sugerem que os fluxos migratórios na direção da região tendem a se intensificar com o advento do COMPERJ, reforçando, porém, certa assimetria no comportamento do mercado de trabalho, reforçando a dificuldade de acesso da população local às ocupações criadas e pressionando os salários no caso de algumas ocupações de baixa qualificação, que acabam dificultando as condições de contratação para empresas locais. No tocante á pendularidade da população local, captada pelo percentual de população residente que trabalhavam ou estudavam fora do município de residência, verifica-se que o mesmo atingia 18,3\% na região, valor expressivamente superior ao observado para o conjunto do estado $(10,1 \%)$. Já no tocante ao tempo habitual de deslocamento para o trabalho, verifica-se que $23,7 \%$ da população gastavam mais de uma hora para viabilizar este deslocamento. Observa-se também que as transformações em curso na região impõem a necessidade de aceleração do ritmo de investimento pelas municipalidades locais. No entanto, quanto a este aspecto, as evidências apontadas na Tabela 3 indicam que o investimento per capita nos municípios da região atingia $\mathrm{R} \$ 166$, valor aproximadamente $53 \%$ inferior ao observado para o conjunto do estado. As despesas em educação por aluno matriculado na rede municipal nos municípios da região também apresentavam valores ligeiramente inferiores ao observado para o conjunto do estado, assim como as despesas com saúde per capita.

A Tabela 4 apresenta informações sobre a situação geral da região em termos de indicadores de renda e pobreza. Informações do censo 2010 apontavam para um rendimento nominal médio mensal domiciliar per capita na região da ordem de $\mathrm{R} \$ 569$, valor aproximadamente $47 \%$ inferior ao observado para o conjunto do estado do Rio de Janeiro. 


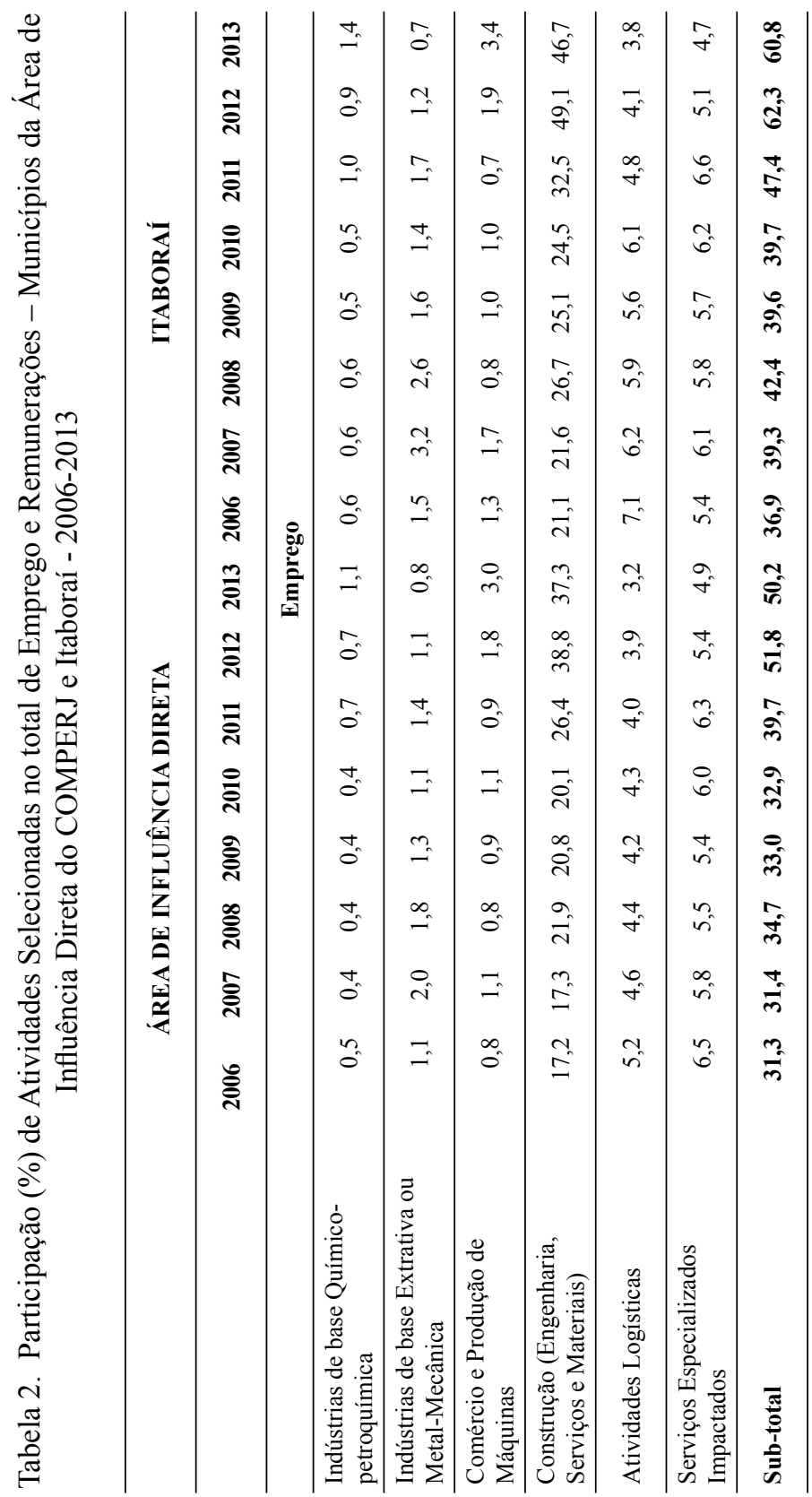




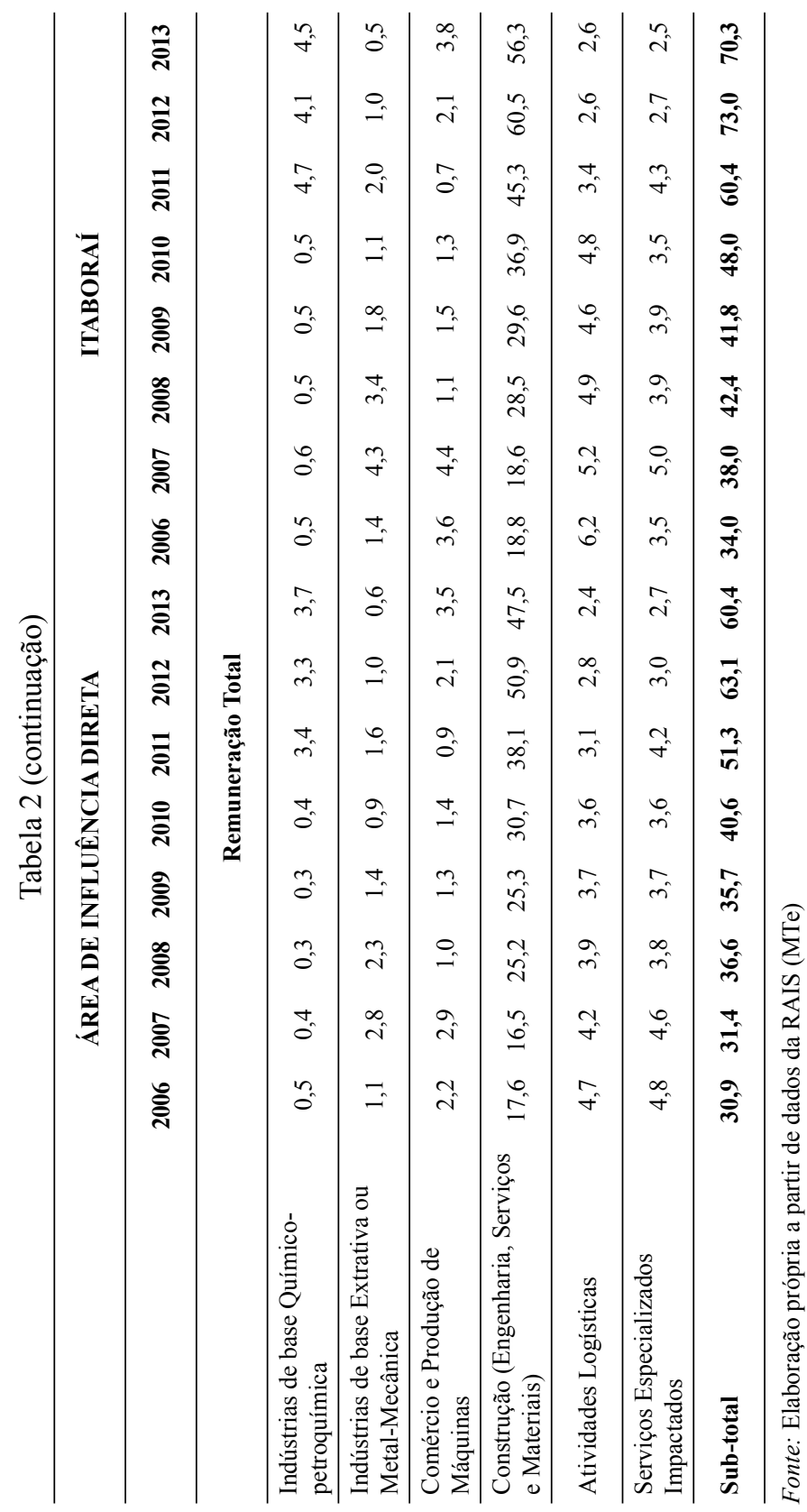




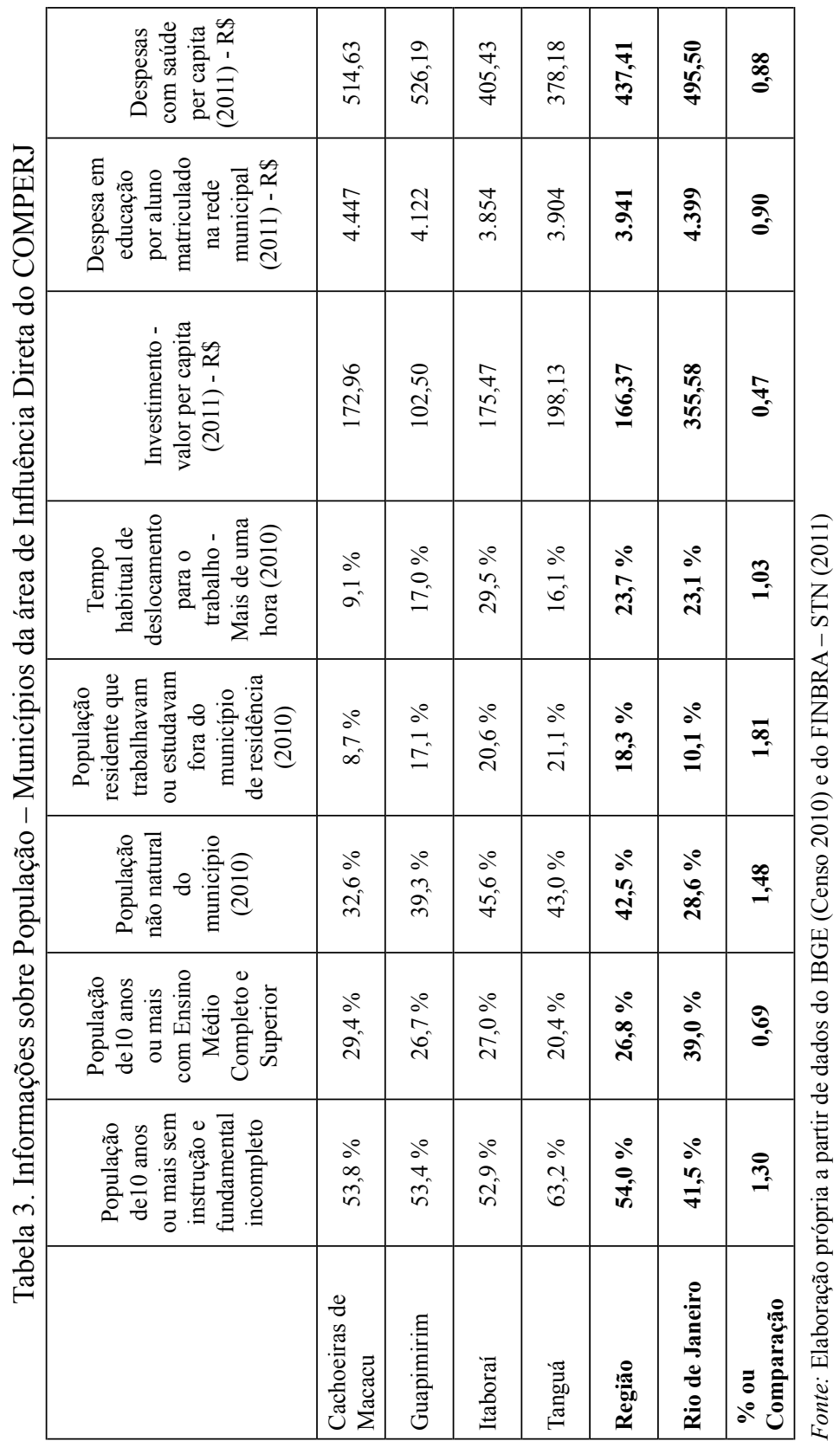


Quando se considera a distribuição de domicílios por faixa de nominal mensal domiciliar per capita alguns contrastes também ficam evidentes: por um lado, $64,5 \%$ dos domicílios da região distribuíam-se na faixa de rendimento igual a ou inferior a um salário mínimo, contra $48,4 \%$ para o conjunto do estado; por outro lado, 1,5\% dos domicílios da região distribuíam-se na faixa de rendimento superior a cinco salários mínimos, contra $8,1 \%$ para o conjunto do estado. Estimativasmais recentes apontavam para um percentual de domicílios abaixo da linha de pobrezal na região de $21,6 \%$, percentual expressivamente superior ao observado para o conjunto do estado. Apesar disso, pode-se observar que a região em análise registrou uma queda importante na porcentagem de domicílios abaixo da linha de pobreza entre 2007 e 2011, passando de $32 \%$ para 21,7\%. Cabe destacar, em relação aos municípios, que se notam quedas generalizadas no patamar de pobreza, com destaque para Cachoeiras de Macacu e Itaboraí, cujas taxas chagaram em 2011 ao patamar respectivo de $16,5 \%$ e $21,7 \%$. Já as localidades de Tanguá (com 29,5 \%, maior patamar em 2011) e Guapimirim (com taxa de $23 \%$ ) se caracterizam por apresentarem os maiores níveis de pobreza em relação à renda domiciliar per capita. A Tabela 4 também apresenta informações sobre a estimativa de famílias pobres segundo o perfil do Bolsa Família, segundo o Censo 2010 - que considera um renda familiar de até $\mathrm{R} \$ 140,00$ por pessoa - e sobre o número de famílias beneficiárias do Programa. No caso das estimativas de famílias pobres, essas apontavam para um total de 7,2\% nos municípios considerados, valor aproximadamente $30 \%$ superior ao observado para o conjunto do estado. Já no caso de famílias beneficiárias do Programa Bolsa Família, o percentual atingia 7,4 \% no caso dos municípios considerados, contra $4,7 \%$ para o conjunto do estado.

Outro aspecto relevante, associado à evolução da renda e ao aumento do emprego na região, diz respeito à desigualdade, medida através da relação entre a renda per capitado $1 \%$ mais rico e dos $20 \%$ mais pobres. Este indicador mostra quantas vezes à renda per capita do estrato de renda do $1 \%$ mais rico é maior do que a renda per capita do estrato de renda dos $20 \%$ mais pobres. Diante disto, observa-se que a desigualdade na região investigada caiu entre 2007 e 2011. Já os municípios seguiram nesta mesma direção com destaque para os municípios de Tanguá e Cachoeiras de Macacu, que foram os municípios que registraram os menores patamares de desigualdade entre as rendas per capita dos estratos do $1 \%$ mais rico e $20 \%$ mais pobres. Já Guapimirim e Itaboraí apresentaram níveis de

1 Foram empregadas as linhas de pobreza domiciliar para o Estado do Rio de Janeiro, fornecidas pelo IPEA (Instituto de pesquisa econômica aplicada). As linhas de pobreza para o Estado são divididas em três categorias: região metropolitana ( $\mathrm{R} \$ 248,35)$, urbana ( $\mathrm{R} \$ 210,72)$ e não urbana (R\$ 189,65). Todos os valores estão em reais de 2011. 
desigualdade mais acentuados com os $1 \%$ mais ricos auferindo uma renda per capita 66,6 e 41,2 vezes maior do que os $20 \%$ mais pobres.

Essas evidências sugerem que, apesar dos investimentos do COMPERJ apresentarem um potencial de modificação do quadro socioeconômico da região adjacente, torna-se necessário remover alguns entraves ao desenvolvimento local e empresarial na região. Os municípios da região, de forma agregada, possuíam relativamente mais pobres do que o Estado do Rio de Janeiro, particularmente em cidades como Guapimirim, Itaboraí e Tanguá, o que reforça a importância de ações localizadas de combate à fome e à pobreza naquelas localidades. As evidências disponíveis apontam a persistência de bolsões de pobreza e desigualdades inter-regionais expressivas na região, apesar de políticas públicas implementadas na região, em especial o Programa Bolsa Família. De forma a contribuir para a eliminação desses bolsões, torna-se necessário implementar programas localizados de geração de emprego e renda na região, de forma articulada à realização de esforços para melhoria da qualificação da população que se destina ao mercado de trabalho. Isto envolve programas localizados de geração de emprego e renda em áreas mais carentes, através da capacitação de empreendedores locais e da mobilização de linhas de microcrédito, assim como a formatação de programas de requalificação da mão de obra para atender a demanda de empregos gerada pela atração de atividades industriais, comerciais e de serviços para a região. Cabe mencionar também a implementação de programas de qualificação da mão de obra da população jovem que se destina ao mercado de trabalho, envolvendo não apenas a educação formal, como também cursos técnicos e profissionalizantes.

Por fim, cabe salientar que os impactos na região estudada assumem dimensões mais profundas, que não são captadas por dados secundários, como os apresentados nesta seção. Em especial, destaca-se a necessidade de um melhor entendimento das condições de renda prevalecentes na região, seja para qualificar possíveis impactos de um empreendimento das dimensões do COMPERJ, seja para avaliar "qualidade" dos recursos humanos disponíveis na região, que pode atuar como fator de entrave ou de estímulo à dinamização do mercado de trabalho. Desta forma, nas próximas seções discutiremos a metodologia e os resultados de pesquisas de campo estruturadas nesta região com a finalidade de se avaliar essas condições, tendo o ano de 2011 como referência. 


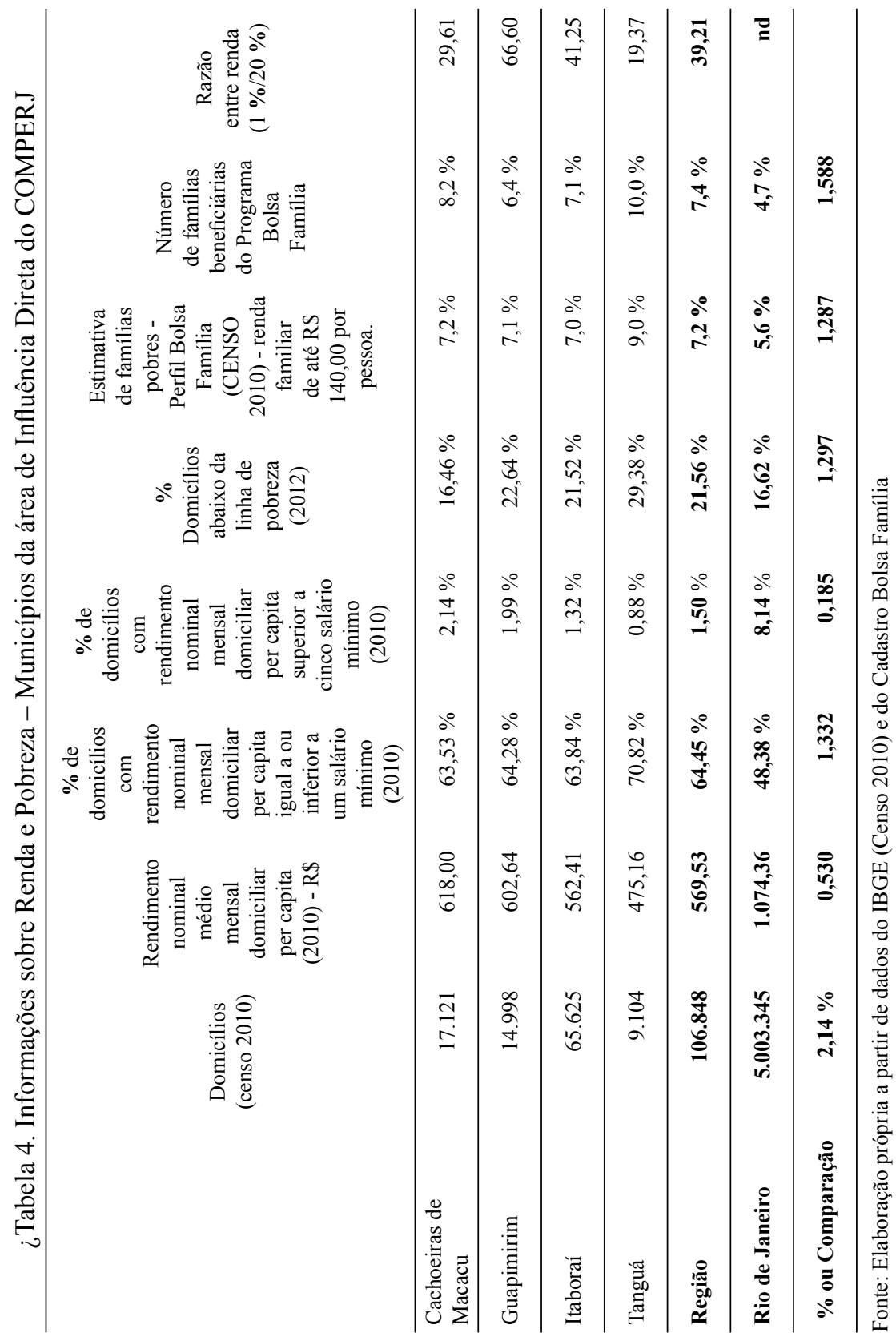




\section{ANÁLISE DAS CONDIÇÕES DE RENDA NOS MUNICÍPIOS DA ÁREA DE INFLUÊNCIA DO COMPERJ: METODOLOGIA DA PESQUISA DE CAMPO}

Um dos objetivos do trabalho foi o de pesquisar os determinantes de renda e pobreza da população do entorno mais próximo ao COMPERJ que, neste caso, corresponde aos Municípios de Itaboraí, Cachoeiras de Macacu, Tanguá e Guapimirim. Para esse fim foi realizada pesquisa de campo por meio de entrevistas aleatórias e representativas, baseadas em cadastros domiciliares com base num Questionário Socioeconômico. Esse questionário contém informações sobre as condições de moradia, características dos moradores, fluxos migratórios, nupcialidade, saúde, escolaridade, trabalho e rendimentos dos indivíduos e das famílias. Com base nessas informações foi possível estimar indicadores de pobreza, renda e migrações de modo a complementar outras análises baseadas em extrapolações de informações secundárias.

O universo da população destes municípios estava composto em 2010 por um total de 354.496 habitantes que residiam em 112.611 em domicílios particulares permanentes ocupados (DPPO), segundo dados do Censo Demográfico 2010 (IBGE, 2011), conforme ilustrado peal Tabela 5. A unidade de análise desta pesquisa não são as famílias, mas os DPPO, que se distribuem entre os municípios da seguinte forma

Foi definido que cada setor censitário 2 com até 350 endereços teria quatro domicílios com entrevista realizada e que cada um dos 14 setores com mais de 350 domicílios, teria seis domicílios entrevistados, selecionados por um procedimento de amostragem inversa (Haldane, 1945), a partir da seleção equiprovável de até 30 endereços por estrato. Na amostragem inversa, os endereços selecionados devem ser visitados sequencialmente, na ordem de seleção, até que sejam obtidas seis entrevistas realizadas. A seleção dos 30 endereços de DP foi feita com equiprobabilidade, utilizando o algoritmo de Hájek (1960), após eliminar os endereços que não eram de domicílios particulares.

2 Os setores censitários são unidades territoriais (urbanas ou rurais), cuja dimensão e número de domicílios servem para orientar a distribuição espacial da população. Cada área do setor censitário é definida por limites territoriais com base em pontos de referência estáveis e de fácil identificação no local. 
Tabela 5. Número de setores, de DPPO e população residente por município

\begin{tabular}{lccccc}
\hline \multicolumn{1}{c}{ Domicílios } & $\begin{array}{c}\text { Cachoeiras } \\
\text { de Macacu }\end{array}$ & Tanguá & Itaboraí & Guapimirim & Total \\
\hline $\begin{array}{l}\text { Total de Setores } \\
\text { Censitários }\end{array}$ & 108 & 69 & 441 & 94 & 712 \\
\hline DPPO & 17.838 & 9.656 & 69.383 & 15.734 & 112.611 \\
\hline População Total & 54.273 & 30.732 & 218.008 & 51.483 & 354.496 \\
\hline
\end{tabular}

DPPO é domicílio particular permanente ocupado. Fonte: Arquivo Agregado por Setores Censitários dos Dados da Sinopse do Censo Demográfico 2010. Disponível em: ftp://ftp.ibge.gov.br/Censos/ Censo_Demografico_2010/Sinopse/Agregados_por_Setores_Censitarios/

Tabela 6. Tamanho da Amostra em cada município

\begin{tabular}{lc}
\hline \multicolumn{1}{c}{ Município } & Tamanho da Amostra DPPO \\
\hline Cachoeira de Macacu & 412 \\
\hline Tanguá & 360 \\
\hline Itaboraí & 1.534 \\
\hline Guapimirim & 340 \\
\hline TOTAL & 2.646 \\
\hline
\end{tabular}

Fonte: Elaboração própria

Conforme ilustrado pela Tabela 6 foram realizadas efetivamente 2.646 entrevistas em diferentes etapas, começando em outubro de 2011 com Cachoeiras de Macacu e Tanguá, seguido por Itaboraí em julho de 2012 e terminando com Guapimirim em dezembro de 2012.3 A fim de subsidiar a coleta de dados foram elaboradas 96 planilhas, uma cada estrato, que fornecem: (1) relação de endereços de DP na ordem em que devem ser visitados (colunas de A até F); e (2) os campos para indicar o resultado de entrevista (coluna $\mathrm{G}$ ) e a numeração sequencial dos DP entrevistados (coluna $\mathrm{H}$ ). $\mathrm{O}$ Esquema probabilístico da amostra foi planejado da seguinte forma:

3 O preenchimento do questionário foi feito por alunos do curso de graduação em Economia da Universidade Federal Fluminense com acompanhamento de funcionários indicados pelas diferentes prefeituras municipais que auxiliaram na localização dos domicílios.Cada entrevistador foi responsável por uma determinada área do município aleatoriamente selecionada para compor a amostra dos indivíduos a serem entrevistados. 
Representando um estrato genérico (de um modo geral, um setor censitário qualquer) pelo índice $\mathrm{h}(\mathrm{h}=1,2, \ldots, 96)$ e um domicílio particular ocupado (DPO) pelo índice i, a probabilidade de inclusão na amostra de um domicílio qualquer de um setor qualquer, denotada por $\mathrm{P}\left(\mathrm{D}_{\mathrm{hi}}\right)$, é dada por:

$$
P\left(D_{h i}\right)=\frac{V_{h}}{N_{h}} \times \frac{A_{h}}{V_{h i}} \times \frac{n_{h}-1}{A_{h}-1} \text { (1) onde: }
$$

$V_{h^{-}}$o número de endereços de DP visitados para obter o número de entrevistas (quatro ou seis) prefixado para o estrato $\mathrm{h}$;

$N_{h}$ - número de endereços de DP do estrato h, obtido no cadastro de domić́lios do setor (ou agrupamento de setores que compõe o estrato);

$A_{h^{-}}$número de DPO que pertencem à subpopulação de interesse (DPO com pelo menos um adulto) do estrato $\mathrm{h}$;

$n_{h^{-}}$número de DPO da subpopulação de interesse a entrevistar no estrato h, prefixado em quatro ou seis, como indicado anteriormente.

Note-se que esta probabilidade de inclusão é dividida em três probabilidades distintas: (1) a probabilidade de o domicílio ser visitado (ou seja de seu endereço ser selecionado); (2) a probabilidade de o domicílio ser elegível (ou de pertencer à subpopulação de interesse) dado que foi visitado; e (3) a probabilidade de ser um dos quatro ou seis primeiros domicílios elegíveis a aceitar a pesquisa. A terceira probabilidade tem um "menos um" no numerador e no denominador correspondente à regra de parada no processo de visita aos domicílios (perda e um grau de liberdade), como indicou Haldane (1945). Esta adaptação do método de Haldane para amostras domiciliares está descrito em Vasconcellos et al. (2005).

Ao longo das visitas aos endereços de DP selecionados, a equipe de campo indicou o resultado da entrevista com os códigos correspondentes. Foram considerados como domicílios pertencentes à subpopulação de interesse os casos com códigos um (entrevista realizada) e três (recusa do domicílio oudo adulto), visto que os casos com códigos cinco (domicílio vago ou sem adultos) e o (domicílio de uso ocasional) não têm adultos moradores; o código sete (domicílio inexistente: demolido, transferido de lugar, etc.) não é um domicílio e o código nove (endereço não encontrado ou inexistente) é um erro de cadastro.

A expansão da amostra foi feita a partir das probabilidades de inclusão dos domicílios na amostra, onde o peso amostral corresponde ao inverso das probabilidades de inclusão. $A_{h}, V_{h}$ No entanto, como a probabilidade de inclusão de um 
DPO inclui a probabilidade de pertencer à subpopulação de interesse , o inverso do produto dessas três probabilidades corresponderia a expandir a subpopulação de interesse para a população total, o que conduziria à superestimação dos totais populacionais, visto que todos os domicílios particulares seriam considerados como ocupados. Assim, o peso amostral (Wh) corresponde, no caso, ao inverso do produto da primeira pela terceira probabilidade da expressão (1), ou seja:

$$
W_{h}=\frac{N_{h} \times\left(A_{h}-1\right)}{V_{h} \times\left(n_{h}-1\right)}
$$

Para estimação pontual, deve-se considerar o peso amostral no cálculo de médias, proporções (porcentagens ou prevalência), totais e razões. Para isso, basta usar a opção (ou comando) de ponderação nos pacotes estatísticos: opção weight SPSS; comando weight no SAS ou Stata, etc. Para tanto, a variável "peso_amostral" deve ser indicada no comando ou opção. A razão é que os pesos amostrais são diferentes por estrato de seleção. Deixar de ter esses cuidados significa subestimar a variância e, portanto, reduzir intervalos de confiança ou aceitar como significantes parâmetros de modelos que de fato não são significantes, dentre outros erros comuns na estimação a partir de amostras complexas.

\section{CONDIÇÕES DE RENDA NOS MUNICÍPIOS DA ÁREA DE INFLUÊNCIA DO COMPERJ: ANÁLISE ECONOMÉTRICA}

Como mencionado anteriormente, um dos objetivos do artigo consiste em estimar uma regressão em que seja possível discorrer sobre o impactodas características dos municípiosna remuneração do trabalho. Os dados foram coletados nas pesquisas de camporealizadas durante o ano de 2012 e são referentes ao ano de 2011.0 escopo da pesquisa é analisar, antes do início do funcionamento do COMPERJ no município de Itaboraí, o perfil socioeconômico dos moradores de cada um dos municípios que sofrerão influência direta do complexo.

\section{V.1. Dados}

A estimação foi baseada nos modelos de Mincer (1958 e 1974), onde a variável dependente é o logaritmo do rendimento médio bruto anual do traba- 
lho recebido em $2011^{4}$.Porém, o foco desta estimação não é medir o retorno do investimento em educação ou diferenças entre gênero e raça, que são vistos em análises convencionais. Mas sim, se é possível captar as principais características dos moradores dos municípios que sofrerão impactos quando o complexo começar a funcionar. Para isso, consideramos as seguintes variáveis como explicativas 5 :

\section{V.1.1. Características individuais dos moradores}

(i) Escolaridade

Em geral, há um consenso de que existe uma relação positiva entre a renda e o nível de escolaridade de um indivíduo. Isto quer dizer que é provável que, em média, uma pessoa com maior nível educacional ou com mais anos de estudo possua uma renda superior comparativamente à outra com menor escolaridade. Autores como Schultz (1975), Becker (1964) e Mincer (1974) formularam a teoria do capital humano. Por esta teoria, a educação deveria ser encarada como uma decisão de investimento, na qual o custo de oportunidade seria o salário de que se abre mão para continuar na escola ou a mensalidade que se paga para estudar e como benefício se obtém a elevação da renda pela maior escolaridade.

Para o caso do Brasil, o artigo de Ramos (1991) busca analisar a relação entre escolaridade e desigualdade de salários por meio da inspeção dos diferenciais de salário entre a mão de obra qualificada e a não qualificada. Entre os resultados encontrados está o acesso a maiores salários em um determinado instante de tempo e a redução do grau de incerteza sobre o fluxo futuro dos rendimentos do trabalho.

Portanto, consideramos que cada nível de escolaridade terá uma remuneração diferente, considerando como referência a categoria sem escolaridade. Desta forma, quanto maior a escolaridade, maior será o rendimento do trabalho. Com isso, os indivíduos que possuem ensino técnico (profissionalizante), superior e pós-graduação completos, terão maiores renumerações do que os demais níveis de escolaridade.

4 Logaritmo é útil para variáveis estritamente positivas com grandes valores e distribuição concentrada como a renda, além de estreitar a amplitude dos valores, tornando estimativas menos sensíveis a observações extremas (outliers).

5 Para saber as características e como foram construídas as variáveis, ver anexo I - tabela de variáveis explicativas. 
(ii) Experiência (Proxy: idade e tempo de ocupação)

Conforme Vergara e Da Silva Wiltgen (1995), o capital humano pode ser considerado como o conjunto de todos os atributos que os indivíduos possuemque são capazes de produzir renda, incluindo escolaridade, inteligência, adaptabilidade, experiência entre outros. Desta forma, a quantidade de experiência que os trabalhadores absorvem individualmente seria capaz de aumentar sua produtividade e, consequentemente, aumentar sua renda. O mesmo ocorre de acordo com Braga (2008), segundo o qual, a produtividade potencial do trabalhador não depende apenas de seu grau de escolaridade formal, mas também do período que este vem desempenhando seu ofício. Portanto, consideramos que quanto maior for à idade dos moradores e se possuem tempo de ocupação acima de nove anos, maior será sua remuneração devido à maior experiência.

(iii) Saúde

Segundo Bloom et al. (2004), os trabalhadores mais saudáveis seriam física e mentalmente mais enérgicos e robustos, contando com maior força e resistência e também com melhor funcionamento cognitivo e maior capacidade de raciocínio. Além disso, estes trabalhadores teriam uma menor propensão a faltar o trabalho por motivo de o próprio estar doente ou algum familiar. O artigo de dos Santos et al. (2012), por sua vez, busca analisar a relação de causalidade entre renda e saúde para o caso brasileiro entre os anos de 1981 e 2007 e um dos resultados encontrados foi à existência de causalidade da saúde sobre a renda, sugerindo que políticas públicas, cujo objetivo seja o de aumentar a renda, devem levar em consideração à saúde da população, caso contrário, os efeitos sobre a educação, acumulação de capital, entre outros podem não ser os desejados. Portanto, consideramos que o indivíduo possuidor de doenças que o impossibilitem de exercer atividades cotidianas terão menores remunerações do trabalho.

\section{V.1.2. Características de ocupação dos moradores}

(i) Atividade Econômica

Os municípios analisados nesta pesquisa são pouco desenvolvidos, apresentam o setor de serviços inflados e são pouco industrializados, sendo assim, apresentam um número baixo de moradores que trabalham nesta atividade econômica. Entretanto, o rendimento do trabalho na indústriaé maior que outros setores por ne- 
cessitar de mão de obra qualificada, com maior nível de escolaridade. Com a implementação docomplexo, em consequência, aumentará a cadeia produtiva nestes municípios e, assim, o número de moradores empregados no setor industrial crescerá.

Porém, o COMPERJ ainda não iniciou as suas atividades, encontrando-se em fase de construção. Portanto, consideramos que os indivíduos que trabalham no setor de construção também recebem maiores rendimentos do que o restante dos moradores, devido ao grande número de construtoras que participam da construção do complexo e das melhorias locais em infraestrutura. Portanto, criamos variáveis dummies para as atividades industriais e as de construção, considerando como referência os moradores que trabalham em outras atividades econômicas.

(ii) Ocupação no setor público

Diversos trabalhos internacionais ${ }^{6}$ a respeito dos diferenciais de salários entre trabalhadores dos setores público e privado apontam evidências favoráveis ao setor público. O artigo de Holanda (2009) apresenta uma resenha sobre o diferencial de salários entre os trabalhadores dos setores público e privado. Segundo o autor, a literatura empírica sobre diferencial de salários entre os setores público e privado no Brasil ${ }^{7}$ também apresenta evidências de que os trabalhadores do setor público recebem, em média, maiores salários do que os trabalhadores do setor privado. Além disso, outro importante resultado encontrado é o de que as características pessoais, principalmente educação, são os principais componentes que explicam o diferencial público-privado no Brasil. Desta forma, com a implementação do COMPERJ, provavelmente o número de moradores que irão trabalhar no setor público irá aumentar. Por este motivo, consideramos na regressão que se os moradores trabalham no setor público, estes, provavelmente, recebem maiores remunerações.

6 GyourkoeTracy (1988), Van der Gaag e Vijverberg (1988), Stelcner, Van der Gaag e Vijverberg (1989), Terrell (1993), Assaad (1997), Heitmueller (2004), Tansel (2005), Glinskaya e Lokshin (2005). 7 Macedo (1985), Saldanha, Maia e Camargo (1988), Ramalho e Urani (1995), Foguel, Gill, Mendonça e Barros (2000), Belluzo, Pazello e Anuatti-Neto (2005), Barbosa Filho, Pessôa e Afonso (2007), Braga (2008) 


\section{V.1.3. Municípios e migrações}

(i) Município

Devido às diferenças socioeconômicas entre os municípios, criamos variáveis dummies para cada um e consideramos como referência o município de Itaboraí, por ser o que apresenta melhores indicadores e ondeserá implementado o COMPERJ.

(ii) Migrações

Alguns trabalhos internacionais como Borjas (1987) e Chiswick (1978) sugerem que os migrantes (indivíduos que não moram no mesmo país/estado em que nasceram) são indivíduos positivamente selecionados, possuindo, em média, melhores características não observáveis que os não migrantes. Conforme o trabalho de Ferreira et al. (2010), há evidências de que os migrantes brasileiros também são, em média, mais aptos, ambiciosos, agressivos, motivados e empreendedores do que os não migrantes. O objetivo do autor é, então, testar a existência desta evidência, isto é, se os brasileiros migrantes constituem um grupo positivamente selecionado da população brasileira. O teste é feito por meio da comparação entre as rendas dos trabalhadores migrantes com a renda dos trabalhadores não migrantes e como resultado foi encontrado que os não migrantes auferem renda inferior a dos migrantes, indicando que os migrantes são realmente positivamente selecionados com relação ao demais.

Portanto, consideramos, na estimação, se os moradores nasceram no município e no estado, além do tempo que eles moram nos respectivos locais. O objetivo é comparar com moradores mais antigos, que moram há mais de 10 anos, se suas remunerações são menores que as dos migrantes.

\section{V.2. Modelo e Resultado}

A partir das variáveis que foram determinadas para realizar as análises referentes às características dos moradores, da ocupação e dos municípios, o modelo teórico é: $\ln$ remun $=\beta_{0}+\beta_{1} M o_{i}+\beta_{2} O c_{i}+\beta_{3} M i_{i}+\varepsilon_{i}$, onde:

$\mathrm{Mo}_{\mathrm{i}}$ - matriz das variáveis relacionadas as características individuias dos moradores, $\mathrm{Oc}_{\mathrm{i}}$ - matriz das variáveis relacionadas as características de ocupação dos moradores, e $\mathrm{Mi}_{\mathrm{i}}$ - matriz das variáveis relacionadas a município e migrações. 
Portanto:

In remun $=\beta_{0}+\beta_{1}$ escola_ $1+\beta_{2}$ escola_ $2+\beta_{3}$ escola_ $3+\beta_{4}$ escola_ $4+\beta_{5}$ escola_5 $5+\beta_{6}$ escola_6 $+\beta_{7}$ escola_ $7+\beta_{8}$ escola_ $8+\beta_{9}$ escola_9 $+\beta_{10}$ escola_ $10+\beta_{11}$ anos $+\beta_{12}$ indust $+\beta_{12}$ const $+\beta_{14}$ setor_public $+\beta_{15}$ tempo_ocup $+\beta_{16}$ dificuldades $+\beta_{17} m_{-}$comperj_1

O método utilizado para estimação foi o de mínimos quadrados ordinários robustos8, realizada por meio do software StataSE. 12. O número total de moradores dos quatros municípios que foram feitas as entrevista foi de 7.969. Porém, para a estimação, só consideramos os moradores com 16 anos ou mais, o que reduziu o número de observações para 3.430 moradores. Após retirar os dados faltantes, os números de observações ficaram em 3.211 moradores.

Foram feitas sete regressões, onde incluímos as variáveis de acordo, primeiramente, com a matriz de dummies referentes à escolaridade, variável idade, matriz de variáveis referentes à ocupação e assim por diante - como pode ser visto no Anexo II. As regressões apresentam a mesma variável dependente e forma funcional, a diferença entre os modelos adicionados está na inclusão de variáveis.

Por se tratar de comparações entre modelos aninhados, devemos considerar o melhor modelo através dos valores dos critérios de informação de Akaike (AIC) e Bayesiano Schwarz (BIC), além do teste F. No caso, o que possuir menores valores dos critérios AIC e/ou BIC é considerado o melhor modelo. Portanto, o melhor é o quinto, no qual não foram consideradas as variáveis referentes à migração.

Contudo, devemos considerar a significância econômica e estatística dos modelos. É importante levar em consideração a magnitude das estimativas dos coeficientes (tamanho e sinal do coeficiente beta estimado), além do tamanho das estatísticas t. Colocar muita ênfase sobre a significância estatística pode levar à falsa conclusão de que uma variável é importante para explicar a variável dependente, embora seu efeito estimado seja moderado. Mesmo que a $5^{\text {a }}$ regressão seja a melhor, por apresentar todas as variáveis estatisticamente significativas e menores valores de critérios de informação. Não podemos considerar o $7^{\circ}$ modelo, o completo, ruim. As variáveis apresentam magnitudes e sinais de acordo com o

8 Os dados são de cross-section e representam características individuais dos moradores entrevistados e, portanto, possuem grandes variações entre as respectivas realidades socioeconômicas. É necessário considerar anteriormente que a regressão apresentará o problema de heterocedasticidade, o que rompe a hipótese do modelo clássico de regressão linear. 
abordado anteriormente, ou seja, possuem significância econômica9. Na $7^{\mathrm{a}}$ regressão, se o indivíduo nasceu no estado e no município, sua remuneração média será, respectivamente, em torno de 0,7 e 1,5 \% menor em relação aos migrantes. Com respeito ao tempo de moradia, podemos constatar que em relação aos moradores que residem a mais de 10 anos nos municípios analisados, os migrantes possuem maiores renumerações. Porém, não é possível afirmar que existe uma relação de proporção direta do aumento da renumeração conforme o tempo de moradia.

Analisando os coeficientes das variáveis em comum com a $5^{\mathrm{a}}$ e $7^{\mathrm{a}}$ regressão, podemos perceber que os valores arredondados dos coeficientes estimados não diferem muito, além de que os sinais dos coeficientes estão de acordo com as hipóteses levantadas no começo desta seção. Os moradores que possuem ensino técnico completo e no mínimo ensino superior completo possuem, ceteris paribus, respectivamente 107 e $145 \%$ a mais que os moradores que não têm escolaridade.

$\mathrm{O}$ aumento de um ano de idade dos moradores implica num aumento da remuneração em 0,6 \%. Em relação ao tempo de ocupação, os que trabalham a mais de nove anos possuem um rendimento em torno de $28 \%$ a mais dos que possuem menos anos de trabalho. Já os que trabalham no setor público e na construção recebem em torno de $18 \%$ a mais dos que não trabalham. Porém, os que trabalham na indústria recebem em torno de $14 \%$ a mais do que os que não trabalham, mesmo que em média a renumeração da mão de obra no setor industrial seja maior que o de construção. Um dos motivos para um maior impacto da remuneração da construção nesses municípios pode ser a influência socioeconômica da construção do COMPERJ. Sobre as dificuldades decorrentes a problemas de saúde, indivíduos que os apresentam, recebem em torno de $24 \%$ a menos do que os indivíduos que não têm problemas. A respeito da diferença entre os municípios, considerando Itaboraí como referência por ser o município em que será instalada o complexo e por possuir melhores condições socioeconômicas, de fato, os moradores dos outros municípios recebem menos do que os moradores de Itaboraí. A magnitude desta diferença depende do nível socioeconômico dos municípios, por este motivo, Tanguá é que possui o menor valor, seus moradores recebem em torno de $35 \%$ a menos do que os de Itaboraí.

9 Foram realizados teste de multicolinearidade e homocedasticidade, além do teste reset. Todos os modelos estimados não apresentam problemas em relação à forma funcional e heterocedasticidade. Não há problema de multicolinearidade das variáveis utilizadas, porém a de ensino fundamental incompleto, tem um valor alto, acima de 5, mas abaixo de 10 . 


\section{CONSIDERAÇÕES FINAIS}

A dinamização do mercado de trabalho, e conseqüentemente da economia local na região impactada pelo COMPERJ, no contexto atual do empreendimento, encontra-se fortemente atrelada à dinâmica do setor de construção, civil e pesada. Em termos do setor de construção, dois tipos de impactos podem ser destacados. Os impactos diretos das obras estariam relacionados à realização de obras de terraplanagem (numa primeira etapa), à construção de redes de transportes por dutos, à montagem de instalações industriais e de estruturas metálicas e de instalações elétricas. Já os impactos sobre infraestrutura viária e urbana estariam relacionados à construção de rodovias e portos, à valorização e especulação fundiária e à construção de edifícios e outras unidades residenciais, com impactos na dinâmica urbana. Os impactos observados envolvem a instalação de construtoras na região, a criação de empregos, o estímulo ao suprimento local de insumos para construção civil e a dinamização comércio varejista de ferragens, madeira e materiais de construção.

Os dados secundários mostram que o percentual de domicílios abaixo da linha de pobreza10 na região de 21,6\%, percentual é ainda expressivamente superior ao observado para o conjunto do estado. Apesar disso, pode-se observar que a região em análise registrou uma queda importante na porcentagem de domicílios abaixo da linha de pobreza entre 2007 e 2011 , passando de $32 \%$ para $21,7 \%$. Cabe destacar, em relação aos municípios, que se notam quedas generalizadas no patamar de pobreza, com destaque para Cachoeiras de Macacu e Itaboraí, cujas taxas chegaram em 2011 ao patamar respectivo de 16,5\% e 21,7 \%. Já as localidades de Tanguá (com 29,5\%, maior patamar em 2011) e Guapimirim (com taxa de $23 \%$ ) se caracterizam por apresentarem os maiores níveis de pobreza em relação à renda domiciliar per capita.

A pesquisa de campo, entretanto, revela os que trabalham na indústria recebem em torno de $14 \%$ a mais do que trabalham em outros setores, menos o de construção. Porém, mesmo que em média a renumeração da mão de obra no setor industrial seja maior que o de construção, os moradores que trabalham neste setor recebem em torno de $18 \%$ a mais que os outros. Um dos motivos para um maior impacto da remuneração da construção nesses municípios pode ser a influência

10 Foram empregadas as linhas de pobreza domiciliar para o Estado do Rio de Janeiro, fornecidas pelo IPEA (Instituto de pesquisa econômica aplicada). As linhas de pobreza para o Estado são divididas em três categorias: região metropolitana $(\mathrm{R} \$ 248,35)$, urbana $(\mathrm{R} \$ 210,72)$ e não urbana $(\mathrm{R} \$ 189,65)$. Todos os valores estão em reais de 2011. 
socioeconômica da construção do COMPERJ. Portanto, mesmo em fase de construção, já é possível estimar o impacto no rendimento do trabalho na área que sofrerá impacto direto.

Para que este impacto seja maior e eficiente, poderiam ser implementadas políticas públicas nestes municípios contemplando investimentos em educação, com foco em ensino técnico, profissionalizante e superior, devido à baixa concentração de mão de obra local qualificada. Esta medida aumentaria a capacitação dos moradores para trabalhar no COMPERJ, e em consequência, diminuiria a desigualdade social local e a migração.

A respeito da diferença entre os municípios, considerando Itaboraí como referência por ser o município em que será instalado o COMPERJ e por possuir melhores condições socioeconômicas, verifica-se que, de fato, os moradores dos outros municípios recebem menos do que os moradores de Itaboraí. Portanto, a diferença socioeconômica, entre os municípios, tende a crescer a partir do funcionamento do complexo petroquímico. Para que o impacto não aumente a desigualdade entre os municípios de Cachoeiras de Macacu, Guapimirim e Tanguá, poderiam ser implementadas políticas públicas de incentivos a investimentos e ao fortalecimento do empreendedorismo ao nível local nestes municípios. 


\section{Anexo I}

\section{Tabela 7. Variáveis explicativas}

\begin{tabular}{|c|c|c|c|c|c|}
\hline Variável & Notação & Disposição & ransformação & Tipo 1 & Nova Notação \\
\hline \multirow{11}{*}{ Escolaridade } & \multirow{11}{*}{ escola } & 0 - Sem escolaridade & $\begin{array}{l}0 \text { - Não } \\
1 \text { - Sim }\end{array}$ & Dummy & Escolsa_O \\
\hline & & 1 - Ensino Fundamental Incompleto & $\begin{array}{l}0 \text { - Não } \\
1 \text { - Sim }\end{array}$ & Dummy & Escolsa_1 \\
\hline & & 2 - Ensino Fundamental Completo & $\begin{array}{l}0 \text { - Não } \\
1 \text { - Sim }\end{array}$ & Dummy & Escolsa_2 \\
\hline & & 3 - Ensino Médio Incompleto & $\begin{array}{l}0 \text { - Não } \\
1 \text { - Sim }\end{array}$ & Dummy & Escolsa_3 \\
\hline & & 4 - Ensino Técnico Incompleto & $\begin{array}{l}0 \text { - Não } \\
1 \text { - Sim }\end{array}$ & Dummy & Escolsa_4 \\
\hline & & 5 - Ensino Médio Completo & $\begin{array}{l}0 \text { - Não } \\
1 \text { - Sim }\end{array}$ & Dummy & Escolsa_5 \\
\hline & & 6 - Ensino Técnico Completo & $\begin{array}{l}0 \text { - Não } \\
1 \text { - Sim }\end{array}$ & Dummy & Escolsa_6 \\
\hline & & 7 - Ensino Superior Incompleto & $\begin{array}{l}0 \text { - Não } \\
1 \text { - Sim }\end{array}$ & Dummy & Escolsa_7 \\
\hline & & 8 - Ensino Superior Completo & $\begin{array}{l}0 \text { - Não } \\
1 \text { - Sim }\end{array}$ & Dummy & Escolsa_8 \\
\hline & & 9 - Pós-Graduaçao Incompleta & $\begin{array}{l}0 \text { - Não } \\
1 \text { - Sim }\end{array}$ & Dummy & Escolsa_9 \\
\hline & & 10 - Pós-Graduaçao Completa & $\begin{array}{l}0 \text { - Não } \\
1 \text { - Sim }\end{array}$ & Dummy & Escolsa_10 \\
\hline Idade & anos & 16 años ou mais & - & Quantitativ & va \\
\hline \multirow{3}{*}{$\begin{array}{l}\text { Atividade } \\
\text { econômica }\end{array}$} & \multirow{3}{*}{ atividade } & 0 - Outra & $\begin{array}{l}0 \text { - Não } \\
1 \text { - Sim }\end{array}$ & Dummy & outra \\
\hline & & 1 - Indústria & $\begin{array}{l}0 \text { - Não } \\
1 \text { - Sim }\end{array}$ & Dummy & indust \\
\hline & & 2 - Construçao & $\begin{array}{l}0 \text { - Não } \\
1 \text { - Sim } \\
\end{array}$ & Dummy & const \\
\hline $\begin{array}{c}\text { Trabalha } \\
\text { no setor público }\end{array}$ & setor_public & $\begin{array}{l}0 \text { - Não } \\
1 \text { - Sim }\end{array}$ & - & Dummy & - \\
\hline $\begin{array}{c}\text { Tempo } \\
\text { de ocupaçao }\end{array}$ & tempo_ocup & $\begin{array}{l}0 \text { - Menos de } 10 \text { anos } \\
1 \text { - Acima de } 10 \text { anos }\end{array}$ & - & Dummy & - \\
\hline \multirow{4}{*}{ Municipio } & \multirow{4}{*}{ m_comperj } & 1 - Cachoeiras de Macau & $\begin{array}{l}0 \text { - Não } \\
1 \text { - Sim }\end{array}$ & Dummy & m_comperj_1 \\
\hline & & 2 - Guapimirim & $\begin{array}{l}0 \text { - Não } \\
1 \text { - Sim }\end{array}$ & Dummy & m_comperj_2 \\
\hline & & 3 - Itaboraí & $\begin{array}{l}0 \text { - Não } \\
1 \text { - Sim }\end{array}$ & Dummy & m_comperj_3 \\
\hline & & 4 - Tanguá & $\begin{array}{l}0 \text { - Não } \\
1 \text { - Sim }\end{array}$ & Dummy & m_comperj_4 \\
\hline $\begin{array}{l}\text { Nasceu no Estado } \\
\text { do Río de Janeiro }\end{array}$ & estado & $\begin{array}{l}0 \text { - Não } \\
1 \text { - Sim } \\
\end{array}$ & - & Dummy & - \\
\hline $\begin{array}{l}\text { Nasceu no respectivo } \\
\text { municipio em que mora }\end{array}$ & municipio & $\begin{array}{l}0 \text { - Não } \\
1 \text { - Sim } \\
\end{array}$ & - & Dummy & - \\
\hline \multirow{5}{*}{$\begin{array}{l}\text { Tempo de moradia } \\
\text { no municipio }\end{array}$} & \multirow{5}{*}{ tempo_morad } & 1 - Menos de 1 ano & $\begin{array}{l}0 \text { - Não } \\
1 \text { - Sim }\end{array}$ & Dummy & tempo_morad1 \\
\hline & & 2 - De 1 a 2 anos & $\begin{array}{l}0 \text { - Não } \\
1 \text { - Sim }\end{array}$ & Dummy & tempo_morad2 \\
\hline & & 3 - De 3 a 5 anos & $\begin{array}{l}0 \text { - Não } \\
1 \text { - Sim }\end{array}$ & Dummy & tempo_morad3 \\
\hline & & 4 -De 6 a 9 anos & $\begin{array}{l}0 \text { - Não } \\
1 \text { - Sim }\end{array}$ & Dummy & tempo_morad4 \\
\hline & & $5-10$ anos ou mais & $\begin{array}{l}0 \text { - Não } \\
1 \text { - Sim } \\
\end{array}$ & Dummy & tempo_morad5 \\
\hline $\begin{array}{l}\text { Possui alguna doença } \\
\text { que impede atividade } \\
\text { cotidiana (saúde) }\end{array}$ & dificuldades & $\begin{array}{l}0 \text { - Não } \\
1 \text { - Sim }\end{array}$ & - & Dummy & - \\
\hline
\end{tabular}

Fonte: Pesquisa de Campo - Dados amostrais dos municipios de Cachoeiras de Macacu, Guapimirim, Itaboraí e tanguá; referente ao ano de 2011. 


\section{Anexo II}

Tabela 8. Comparação das regressões

\begin{tabular}{|c|c|c|c|c|c|c|c|}
\hline Variável & Regressão 1 & Regressão 2 & Regressão 3 & Regressão 4 & Regressão 5 & Regressão 6 & Regressão 7 \\
\hline \multirow[t]{2}{*}{ escola_l } & 0,4418 & 0,5554 & 0,5324 & 0,5107 & 0,4379 & 0,4363 & 0,4358 \\
\hline & 0,0000 & 0,0000 & 0,0000 & 0,0000 & 0,0000 & 0,0000 & 0,0000 \\
\hline \multirow[t]{2}{*}{ escola_2 } & 0,8764 & 0,9814 & 0,9397 & 0,9169 & 0,8932 & 0,8901 & 0,8861 \\
\hline & 0,0000 & 0,0000 & 0,0000 & 0,0000 & 0,0000 & 0,0000 & 0,0000 \\
\hline \multirow[t]{2}{*}{ escola_3 } & 0,1500 & 0,3454 & 0,3425 & 0,3257 & 0,3415 & 0,3365 & 0,3309 \\
\hline & 0,2618 & 0,2618 & 0,0105 & 0,0135 & 0,0104 & 0,0117 & 0,0131 \\
\hline \multirow{2}{*}{ escola_4 } & 0,6510 & 0,8217 & 0,7389 & 0,7055 & 0,7358 & 0,7284 & 0,7187 \\
\hline & 0,0001 & 0,0000 & 0,0000 & 0,0000 & 0,0000 & 0,0000 & 0,0000 \\
\hline \multirow[t]{2}{*}{ escola_5 } & 0,6650 & 0,8118 & 0,7773 & 0,7445 & 0,8219 & 0,8202 & 0,8182 \\
\hline & 0,0000 & 0,0000 & 0,0000 & 0,0000 & 0,0000 & 0,0000 & 0,0000 \\
\hline \multirow[t]{2}{*}{ escola_6 } & 0,9054 & 1,0240 & 1,0565 & 1,0077 & 1,1748 & 1,1748 & 1,1663 \\
\hline & 0,0000 & 0,0000 & 0,0000 & 0,0000 & 0,0000 & 0,0000 & 0,0000 \\
\hline \multirow[t]{2}{*}{ escola_7 } & 0,6640 & 0,8639 & 0,8449 & 0,8109 & 0,8187 & 0,8187 & 0,8218 \\
\hline & 0,0000 & 0,0000 & 0,0000 & 0,0000 & 0,0000 & 0,0000 & 0,0000 \\
\hline \multirow[t]{2}{*}{ escola_8 } & 1,3244 & 1,4451 & 1,4111 & 1,3792 & 1,4575 & 1,4575 & 1,4441 \\
\hline & 0,0000 & 0,0000 & 0,0000 & 0,0000 & 0,0000 & 0,0000 & 0,0000 \\
\hline \multirow[t]{2}{*}{ escola_9 } & 1,4439 & 1,5173 & 1,3841 & 1,3791 & 1,4489 & 1,4489 & 1,4424 \\
\hline & 0,0000 & 0,0000 & 0,0000 & 0,0000 & 0,0000 & 0,0000 & 0,0000 \\
\hline \multirow[t]{2}{*}{ escola_10 } & 1,6091 & 1,5653 & 1,5003 & 1,4498 & 1,4669 & 1,4669 & 1,4628 \\
\hline & 0,0000 & 0,0000 & 0,0000 & 0,0000 & 0,0000 & 0,0000 & 0,0000 \\
\hline \multirow[t]{2}{*}{ anos } & & 0,0086 & 0,0038 & 0,0055 & 0,0059 & 0,0059 & 0,0058 \\
\hline & & 0,0000 & 0,0133 & 0,0004 & 0,0001 & 0,0001 & 0,0003 \\
\hline \multirow{2}{*}{ tempo_ocup } & & & 0,2761 & 0,2771 & 0,2834 & 0,2834 & 0,2859 \\
\hline & & & 0,0000 & 0,0000 & 0,0000 & 0,0000 & 0,0000 \\
\hline \multirow[t]{2}{*}{ setor_public } & & & 0,1770 & 0,1761 & 0,1754 & 0,1754 & 0,1805 \\
\hline & & & 0,0000 & 0,0000 & 0,0000 & 0,0000 & 0,0000 \\
\hline \multirow[t]{2}{*}{ indust } & & & 0,1234 & 0,1220 & 0,1370 & 0,1370 & 0,1358 \\
\hline & & & 0,0525 & 0,0547 & 0,0295 & 0,0295 & 0,0305 \\
\hline \multirow[t]{2}{*}{ const } & & & 0,1782 & 0,1779 & 0,1787 & 0,1787 & 0,1783 \\
\hline & & & 0,0000 & 0,0000 & 0,0000 & 0,0000 & 0,0000 \\
\hline \multirow[t]{2}{*}{ dificuldades } & & & & $-0,2519$ & $-0,2400$ & $-0,2400$ & $-0,2401$ \\
\hline & & & & 0,0000 & 0,0000 & 0,0000 & 0,0000 \\
\hline m_comperj_l & & & & & $-0,2189$ & $-0,2189$ & $-0,2138$ \\
\hline$m_{-}$comperj_t & & & & & 0,0000 & 0,0000 & 0,0000 \\
\hline m_comperj_2 & & & & & $-0,1392$ & $-0,1392$ & $-0,1390$ \\
\hline & & & & & 0,0014 & 0,0014 & 0,0016 \\
\hline m_comperj_4 & & & & & $-0,3487$ & $-0,3487$ & $-0,3494$ \\
\hline & & & & & 0,0000 & 0,0000 & 0,0000 \\
\hline estado & & & & & & $-0,0039$ & $-0,0071$ \\
\hline & & & & & & 0,9355 & 0,8829 \\
\hline municipio & & & & & & $-0,0360$ & $-0,0148$ \\
\hline & & & & & & 0,2791 & 0,6668 \\
\hline tempo_moradl & & & & & & & 0,0257 \\
\hline & & & & & & & 0,8427 \\
\hline tempo morad2 & & & & & & & 0,0357 \\
\hline & & & & & & & 0,6869 \\
\hline tempo morad 3 & & & & & & & 0,0092 \\
\hline & & & & & & & 0,9103 \\
\hline tempo morad4 & & & & & & & 0,1612 \\
\hline & & & & & & & 0,0264 \\
\hline cons & 8,6760 & 8,2154 & 8,2658 & 8,2554 & 8,3472 & 8,3809 & 8,3536 \\
\hline & 0,0000 & 0,0000 & 0,0000 & 0,0000 & 0,0000 & 0,0000 & 0,0000 \\
\hline $\mathrm{N}$ & 3211 & 3211 & 3211 & 3211 & 3211 & 3211 & 3211 \\
\hline $\mathrm{r} 2$ & 0,0762 & 0,0935 & 0,1269 & 0,1375 & 0,1500 & 0,1505 & 0,1524 \\
\hline $\mathrm{F}$ & 22,6097 & 24,3045 & 26,6714 & 26,7977 & 25,2499 & 23,0471 & 19,5522 \\
\hline घ & $-3756,2384$ & $-3725,8227$ & $-3665,5580$ & $-3645,9654$ & $-3622,5599$ & $-3621,6320$ & $-3618,0184$ \\
\hline aic & 7534,4768 & 7475,6453 & 7363,1160 & 7325,9308 & 7285,1198 & 7287,2639 & 7288,0368 \\
\hline bic & 7601,2946 & 7548,5374 & 7460,3054 & 7429,1946 & 7406,6065 & 7420,8994 & 7445,9696 \\
\hline
\end{tabular}

legenda: coeficiente/p-valor 


\section{REFERÊNCIAS}

Assad, R. (1997). The effects of public sector hiring and compensation policies on the Egyptian labor market. The World Bank Economic Review, 11 (1).

Barbosa, S. R. C. S. (2008). Ambiente, subjetividade e complexidade: um estudo sobre depressão no litoral norte paulista. Relatório Científico, FAPESP (processo n. 04/10685-1).

Barbosa Filho, F. H., Pessôa, S. A. \& Afonso, L. E. (2009). Um estudo sobre os diferenciaisde remuneração entre os professores das redes pública e privada de ensino. Estudos Econômicos (São Paulo), 39 (3), 597-628.

Becker, G. S. (1964). Human capital. New York: Columbia University Press.

Belluzo, W., Pazello, E. \& Anuatti-Neto, F. (2005). Distribuição de salários e diferencial público-privado no Brasil. Revista Brasileira de Economia, 59 (4), out./dez. 511-533.

Benko, G., \& Pecqueur, B. (2001). Os recursos de territórios e os territórios de recursos. Geosul, 16 (32), jul./dez, 31-50.

Bloom, D. E., Canning, D., \& Sevilla, J. (2004). The Effect of Health on Economic Growth: A Production Function Approach. World Development, 32 (1), 1-13.

Boisier, S. (2005). ¿Hay espacio para el desarrollo local en la globalización? Revista de la CEPAL, (86), 47-62.

Borjas, G. J., Bronars, S. G., \& Trejo, S. J. (1992). Self-Selection and Internal Migration in the United States. Journal of Urban Economics, 32, 159-185.

Braga, B. G. (2008). Educação, experiência e o hiato salarial entre o setor público e privado no Brasil. Dissertação (Mestrado) - Pontifícia Universidade Católica do Rio de Janeiro, Rio de Janeiro.

Casanova, F. (2004). Local development, productive networks and training: alternative approaches to training and work for young people. Montevideo: OIT-Cinterfor.

Chiswick, B. R. (1978). The Effect of Americanization on the Earnings of Foreign-Born Men. Journal of Political Economy, 86, 897-921.

Christopherson, S. Michie, J., \& Tyler, P. (2010). Regional resilience: theoretical and empirical perspectives. Journal of Political Economy, 86, 897-921.

Colletis, G., Gilly, J., Leroux, I., Pecqueur, B., Perrat, J., Rychen, F. \& Zimmermann, J. (1999). Construction territoriale et dynamiques productives. G.R.E.Q.A.M., Universite Aix-Marseille III.

Santos dos, A. M. A., Jacinto, P. A. \& Tejada, C. A. O. (2012). Causalidade entre Renda e Saúde: Uma Análise Através da Abordagem de Dados em Painel com os Estados do Brasil. Estudos Econômicos (São Paulo), 42(2), abr.-jun, 229-261. 
Ferreira, P. C. G., Santos Júnior dos, E. R. \& Menezes Filho, N. A. (2010). Migração, seleção e diferenças regionais de renda no Brasil, Rio de Janeiro, EPGE Ensaios Econômicos, 484.

Foguel, M. N., Gill I., Mendonça, R., \& Barros, R. P. de. (2000). The public-private wage gap in Brazil. Revista Brasileira de Economia, 54 (4), Oct.-Dec, 433-472.

Glinskaya, E., \& Lokshin, M. (2005). Wage differentials between the public and private sectors in India. World Bank Policy Research Paper, No. 3.574.

Gyourko, J., \& Tracy, J. (1988). An analysis of public-private sector wages allowing for endogenous choices of both government and union status. Journal of Labor Economics, 6 (2), 229-253.

Hájek, J. (1960). Limiting distribution in sample random sampling from finite populations. Publication of the Mathematics Institute of the Hungarian Academy of Science, Series A, 5, 361-374.

Haldane, J. B. S. (1945). On a method of estimating frequencies. Biometrika, 33 (3), 222-225.

Heitmueller, A. (2004). Public-private sector wage differentials in Scotland: an endogenous switching model. Institute for the Study of Labor (IZA), Discussion Paper No. 992.

Holanda, A. L. N. (2009). Diferencial de salários entre os setores público e privado: uma resenha da literatura. Brasília.

IBGE - Fundação Instituto Brasileiro de Geografia e Estatística (2011). Sinopse do Censo Demográfico 2010. Rio de Janeiro: IBGE.

Macedo, R. (1985). Diferenciais de salários entre empresas privadas e estatais no Brasil. Revista Brasileira de Economia, 39 (4), 437-448.

Maillat, D. \& Kelbir, L. (1999). Learning region et systemes territoriaux de production. Revue d'économie régionale et urbaine, 3, 429-448.

Mincer, J. (1958) Investment in human capital and personal income distribution. Journal of Political Economy, 66 (4), 281-302.

Mincer, J. (1974). Schooling, experience, and earnings. New York: Columbia University Press.

Noronha, K., Figueiredo, L. K., \& Andrade, M. V. (2010). Health and economic growth among the states of Brazil from 1991 to 2000. Revista Brasileira de Estudos Populacionais, 27, 269-283.

OECD - Organisation for Economic Co-Operation and Development (2001). Local Governance and Partnerships: A Summary of the Findings of the OECD.

Paelinck, J. (1977). A teoria do desenvolvimento regional polarizado. In J. Schwartzman. Economia regional: textos escolhidos (157-194). Belo Horizonte: Cedeplar. 
Perroux, F. (1955). Note sur la notion de Pôle de Croissance. Économie Appliquée, $8(1-2), 307-320$.

Pessoa D. G. C. \& Silva P. L. N. (1998). Análise de Dados Amostrais Complexos. São Paulo: Associação Brasileira de Estatística.

Ramalho, M. \& Urani, A. (1955). A administração pública como empregadora: uma avaliação da década de 80. Rio de Janeiro: Instituto de Pesquisa Econômica Aplicada. Série Seminários, 5/95.

Ramos, L. (1991). Educação, desigualdade de renda e ciclo econômico no Brasil, Pesquisa e Planejamento Econômico, 21 (3), 559-574.

Renk, M. (2016). Transporte e armazenamento de hidrocarbonetos em áreas costeiras: um estudo sobre percepção de riscos em municípios do litoral norte paulista. (Tese de Doutorado). Universidade Estadual de Campinas, São Paulo.

Saldanha, R., Maia, R. \& Camargo, J. M. (1988). Emprego e salário no setor público federal. Texto para Discussão N. ${ }^{\circ}$. 5. Brasília: Ministério do Trabalho.

Seixas, S. \& Renk, M. (2010). Projetos do setor de petróleo e gás no sudeste brasileiro: algumas considerações sobre o desafio desenvolvimento x preservação ambiental. Em S. Herculano \& H. D. Correa. Impactos sociais, ambientais e urbanos das atividades petroliferas: o caso de Macaé (cap. 4-3, 443-455).

Schultz, T. (1975). The value of the ability to deal with disequilibira. Journal of Economic Literature, 13 (3), 827-846.

Stelcner, M., Van Der Gaag, J., \& Vijverberg, W. (1989). A switching regression modelof public-private sector wage differentials in Peru: 1985-86. The Journal of Human Resources, 24 (3), 545-559

Tansel, A. (2005). Public-private choice, wage differentials, and gender in Turkey. Economic Development and Cultural Change, 53 (2), 453-477.

Terrell, K. (1993). Public-private wage differentials in Haiti: do public servants earn a rent? Journal of Development Economics, 42 (2), 293-314.

Van Der Gaag, J., \& Vijverberg, W. (1988). A switching regression model for wagedeterminants in the public and private sector of a developing country. The Review of Economics and Statistics, 70 (2), 244-252.

Vasconcellos, M. T. L, Silva, P. L. N., \& Szwarcwald, C. L. (2005). Sampling design for the World Health Survey in Brazil. Cadernos de Saúde Pública, 21, Suppl. 1, 89-99.

Vergara, D. H. \& Da Silva Wiltgen, R. (1995). Os diferenciais de salários entre o setor público e o setor privado na RMPA. Indicadores Econômicos FEE, 23 (3), 255-270.

Weil, D. (2007). Accounting for the effect of health on economic growth. The Quarterly Journal of Economics, 122 (3), 1265-1306. 
White, S., \& Gasser, M. (2001). Local economic development: a tool for supporting locally owden and managed development processes that foster the global promotion of decent work. Genebra: Departamento de Criação de Emprego e Desenvolvimento Empresarial da OIT.

(C) 2017 por los autores; licencia otorgada a la revista Estudios económicos. Este artículo es de acceso abierto y distribuido bajo los términos y condiciones de una licencia Atribución-No Comercial 3.0 Unported (CC BY-NC 3.0) de Creative Commons. Para ver una copia de esta licencia, visite http://creativecommons.org/ licenses/by-nc/3.0/ 